\title{
智能制造推动我国制造业全面创新升级
}

\author{
钟志华 $^{1}$, 嚚冀原 ${ }^{2}$, 延建林 ${ }^{2}$, 苗仲桢 ${ }^{3}$, 杨晓迎 ${ }^{2}$ ，古依莎娜 ${ }^{2}$ \\ （1. 中国工程院，北京 100088；2. 中国工程院战略咨询中心，北京 100088；3. 清华大学公共管理学院，北京 100084）
}

\begin{abstract}
摘要：我国抓牢新一轮科技革命和产业变革的历史机遇，加快发展智能制造并取得了积极成效。也要注意到，我国智能制 造整体发展仍处于初级阶段, 不平衡不充分的矛盾较为突出, 持续深入推进智能制造面临挑战。近年来, 我国启动了从制 造大国迈向制造强国的发展进程, 加快制造业由大变强、全面创新升级的发展步伐, 但升级的技术路线仍需更加明确。研 究认为, 新时期新阶段我国制造业要实现全面创新升级, 应坚持智能制造发展的主攻方向, 优化调整总体技术路线, 即数 字化制造、数字化网络化制造、数字化网络化智能化制造 “并行推进、融合发展” ; 企业实施智能制造战略, 应深度融合 数字化网络化智能化赋能技术、先进制造技术, 注重产品创新、生产创新、模式创新、制造系统集成创新, 力争实现整体 性突破。
\end{abstract}

关键词：中国制造；智能制造；数字化制造；数字化网络化制造；数字化网络化智能化制造

中图分类号: F424 文献标识码: A

\section{Intelligent Manufacturing Promotes the Comprehensive Upgrading and Innovative Growth of China's Manufacturing Industry}

\author{
Zhong Zhihua ${ }^{1}$, Zang Jiyuan ${ }^{2}$, Yan Jianlin ${ }^{2}$, Miao Zhongzhen ${ }^{3}$, Yang Xiaoying ${ }^{2}$, Gu Yishana ${ }^{2}$
}

(1. Chinese Academy of Engineering, Beijing 100088, China; 2. Center for Strategic Studies, Chinese Academy of Engineering, Beijing 100088, China; 3. School of Public Policy \& Management, Tsinghua University, Beijing 100084, China)

\begin{abstract}
Over the past few years, China has seized a historical opportunity to expedite the development of intelligent manufacturing driven by a new round of scientific and technological revolution and industrial transformation. However, the overall development of China's intelligent manufacturing is still in its infancy. Issues of the unbalanced and inadequate development of intelligent manufacturing remain prominent in China, which could pose great challenges to its future development. In the forthcoming era, China must focus on the comprehensive development of intelligent manufacturing in order to cultivate a manufacturing industry that is both large in scale and strong in its capabilities. The central technology theme is to promote parallel progress and integrated development of "digitalized manufacturing", "digitalized and networked manufacturing", and "digitalized, networked, and intelligent manufacturing." It is essential to integrate digitalized, networked, and intelligent enabling technologies with advanced manufacturing technologies when adopting intelligent manufacturing. In the meantime, firms should search for comprehensive breakthroughs in products and process innovation as well as advances in business models and integrated manufacturing systems. Consequently, the development of intelligent
\end{abstract}

收稿日期 : 2020-08-21; 修回日期 : 2020-10-28

通讯作者：藏冀原，中国工程院战略咨询中心高级工程师，研究方向为智能制造理论与方法; E-mail: zangjy@cae.cn

资助项目：中国工程院咨询项目 “面向 2035 推进制造强国建设战略研究” (2019-ZD-09)

本刊网址：www.engineering.org.cn/ch/journal/sscae 
manufacturing will facilitate the pioneering development and intelligent upgrading of manufacturing firms.

Keywords: China Manufacturing; intelligent manufacturing; digitalized manufacturing; digitalized and networked manufacturing; digitized, networked, and intelligent manufacturing

\section{一、发展智能制造是我国制造业创新升级的 主攻方向}

全球制造业迎来了以数字化网络化智能化为 发展方向的深刻变革，以新一代信息技术与先进制 造技术深度融合为基本特征的智能制造，已成为这 次新工业革命的核心驱动力 [1]。我国是制造大国, 我国制造业正处于创新升级的重要历史关头，抓牢 全球制造业变革带来的历史机遇, 主动融入新一轮 科技革命和产业变革, 加快发展智能制造, 是由大 变强、全面创新升级的必由之路 [2]。

\section{（一）智能制造是我国制造业实现创新发展的内在 需求}

当前, 我国经济已由高速增长阶段迈入高质 量发展阶段, 社会发展的主要矛盾发生深刻变化, 我国制造业面临的需求和环境也出现了深刻改变。 整体来看, 我国制造已经从总体供给不足过渡到 有效供给不足, 现有制造产品和服务已不能适应 消费结构升级的需要; 我国制造业的技术创新能 力、资源利用效率、质量效益水平等与世界制造 强国尚有不小差距, 整体处于全球价值链中低端 水平的格局尚未得到根本性改变。我国制造业面 临着全面转型升级、全面创新发展、高质量发展 的迫切需求 [3]。

我国制造业要实现转型升级、创新发展, 根本 出路在于进一步深化制造业供给侧结构性变革, 依 靠技术进步满足广大企业创新和转型升级的迫切需 求, 尤其要加快发展智能制造, 推动制造业数字化 网络化智能化的发展步伐, 实施制造企业数字化转 型; 提升制造业的整体技术水平和运营水平，优化 制造产品品质和服务质量, 提高制造业劳动生产率 和经济效益, 改变传统制造业的技术模式、生产方 式、运营模式，使制造供给体系更好适应消费体系、 市场环境的变化, 带动制造业实现质量变革、效率 变革、动力变革 $[4]$ 。

\section{（二）智能制造为我国制造业创新发展提供了历史 性机遇}

2000 年以来, 以大数据、工业互联网、人工智 能（AI）等为代表的新一代信息技术迅猛发展, 相 关群体性技术突破不断涌现, 特别是新一代 AI 技 术、先进制造技术深度融合形成的新一代智能制造 技术，已经成为推动新一轮工业革命的核心驱动 力 [5]。世界各国广泛关注这场以智能制造为核心 的制造业变革, 工业强国普遍将智能制造作为推动 制造业创新发展、巩固并重塑制造业竞争优势的战 略选择。发展智能制造业已成为提升国家竞争力、 赢得未来竞争优势的关键举措。

全球新一轮科技革命和产业变革，为我国制造 业的全面创新升级带来了新的历史机遇。我国在制 造领域、现代信息技术领域都建立了规模庞大、门 类齐全的产业体系, 形成了结构完整、配套健全的 供应链网络。作为工业制造与信息技术融合发展的 交汇点, 智能制造引领和推动新一轮工业革命, 将 进一步促进我国新一代信息技术、先进制造技术的 深入融合, 助推传统产业实施技术优化升级, 支持 新兴产业培育和发展, 带动新技术、新产品、新装 备发展, 催生新的经济增长点, 推动制造业迈入数 字化网络化智能化阶段，促成我国制造业的历史性 重大变革 [6]。

\section{二、推进智能制造持续深入发展任重道远}

近年来, 我国启动了从制造大国迈向制造强国 的发展进程, 为了加快制造业由大变强、全面创新 升级的发展步伐, 明确将智能制造作为建设制造强 国的主攻方向、实现制造业创新发展的主要抓手、 推动制造业转型升级的主要路径 [6]。在工业界和 科技界的共同支持下，我国制造业数字化网络化智 能化转型的步伐不断加快, 智能制造发展取得积极 成效; 但由于各地区、各行业的制造企业生产力发 展水平参差不齐, 智能制造仍整体处于起步阶段, 
发展不平衡不充分的矛盾较为突出, 持续推进智能 制造面临挑战。

\section{（一）制造企业具有旺盛的智能升级需求, 但智能 制造的实施路径不够清晰}

2018 年, 中国工程院制造强国建设研究课题 组在全国 11 个城市、 22 个行业、1859 家企业开展 的问卷调研显示, 制造企业对智能制造表现出了强 烈愿望和积极性, 一批企业已经探索实施智能化改 造升级; $73.0 \%$ 的企业具有强烈的智能化改造需求, $24.0 \%$ 的企业已拥有智能化改造计划, $51.56 \%$ 的 企业为解决用工问题而开展智能化改造; $45.31 \%$ 的 企业以提升产品质量为目的， $28.13 \%$ 的企业计划 对部分生产环节实施针对性的数字化改造， $34.38 \%$ 的企业计划建设数字化智能化工厂 [7]。

可以认为, 智能制造基本理念已经得到国内诸 多行业制造企业的高度认可, 智能制造发展已经逐 步从理念普及转向实际应用推广。由于智能制造是 一种新的制造生产方式, 特别是新一代信息技术、 制造技术的深度融合仍在快速发展变化, 我国各行 业、各地区制造企业发展智能制造的实际条件 “千 差万别”, 许多企业还存在认识困惑、实践误区, 突出体现在智能制造的发展理念、发展方向、发展 重点、路径选择、实施策略等方面 [8]。因此, 诸 多企业实施智能制造的具体技术路径还需探索和实 践, 已有的智能制造推进力度还不匹配广大企业的 实际需求。

\section{（二）智能制造试点示范成效明显, 但在中小企业 全面推广面临挑战}

近年来, 各地区大力开展智能制造应用试点工 作, 推进示范项目、推广典型经验; 一批具有国际 先进水平的数字化车间、数字化网络化工厂投入使 用, 一些制造工厂实现了更高程度的自动化、机械 化、智能化, 产品质量和经济效益得到大幅提升。 相关调查显示 [9], 按照平均数计算, 全国智能制 造试点示范项目企业生产效率提高约 45\%, 产品研 制周期缩短约 35\%, 产品不良品率降低约 35\%, 能 源利用率提升约 $20 \%$, 运营成本下降约 $25 \%$ 。这表 明, 我国智能制造试点工作取得了较为显著的示范 带动效应。

同时要清醒地认识到, 我国多数企业, 特别是
广大中小企业布局智能制造面临着现实困难。一方 面, 绝大部分中小企业的利润水平极低、盈利能力 薄弱, 自有技术、资金、人才积累严重不足, 实施 智能制造面临着试错成本和风险; 另一方面, 细分 行业解决方案与中小企业需求结合不够紧密, 低成 本、高可靠、易维护的解决方案更是缺乏。2018 年, 浙江省智能制造专家委员会对本省 12 个县 (市、区) 的 280 余家制造企业调研, 发现中小企业推进智能 制造面临六方面难题：企业自身改造难、企业 “智 改” 决策拍板难、企业寻找放心的承包商难、企业 持续推进升级难、生产系统健康管理难、多主体运 作形成合力难。

\section{（三）智能制造产业生态体系逐渐形成，但智能制 造升级供给能力存在不足}

我国在推动发展智能制造的过程中, 重视加强 “产学研用” 协同创新, 注重引导企业加强关键技 术装备、核心工业软件、解决方案的研发应用, 加 强智能制造基础支撑能力建设。与智能制造装备、 软件及系统集成服务相关的一批企业、产业园区在 全国各地迅速成长, 成为智能制造产业发展壮大的 孵化器、有生力量; 一批智能制造装备取得突破, 国家智能制造标准体系发布, 智能制造标准国际合 作成果丰硕, 智能制造产业生态体系正在形成, 万 亿元级规模的智能制造市场稳步壮大。

相较于智能制造发展的旺盛需求, 我国智能制 造整体供给能力仍然面临差距。智能制造核心技术 装备自主化程度不高, 不少高档数控机床、专用智 能制造装备、核心零部件主要依赖进口, 存在着产 业技术 “空心化” 的危险。一些地区的智能制造系 统解决方案供给能力不足, 硬件和软件体系完整、 行业积累深厚、能提供整体智能制造解决方案的供 应商普遍缺乏, 领军企业在技术、产品、服务方面 与国际先进厂商有较大差距; 支持企业创新的智能 制造公共支撑平台建设滞后, 智能制造人才培养不 足以保障实际需求。

\section{三、“并行推进、融合发展” 是我国智能制 造发展的技术路线}

智能制造是先进制造技术、先进信息技术的深 度融合，在迭代融合演进过程中逐步形成了 3 种基 
本范式: 数字化制造、数字化网络化制造、数字化 网络化智能化制造 [5]。在发达工业化国家, 这些 基本范式是一个递次演进、“串联式”的发展技术 路线。作为工业化后发国家, 我国在发展智能制造 过程中要同时面对数字化制造、数字化网络化制造、 数字化网络化智能化制造所伴生的挑战。因此, 我 国智能制造发展宜采用 3 种智能制造基本范式 “并 行推进、融合发展”的技术路线 $[9,10]$ 。

\section{（一）数字化制造}

作为第一代智能制造的基本范式，数字化制造 基于数字技术在制造业中广泛应用而形成, 重点解 决问题有：优化生产流程、缩短产品研发周期、降 低制造成本、强化产品质量控制、提高企业劳动生 产率等。自 20 世纪 80 年代起, 我国企业逐步采用 数字化控制系统和制造装备, 同步将数字化技术应 用于设计、制造、管理等过程来推动企业信息化转 型, 取得了良好成效。近年来, “机器换人” “数字 化改造” 项目遍地开花, 建成了一批数字化生产线、 数字化车间、数字化工厂，标志着我国数字化制造 迈入新发展阶段。

需要指出的是，各地区制造业发展水平差异明 显, 还有一批制造业企业, 特别是广大中小企业仍 处在从机械化转向数字化的初级阶段, 信息化、自 动化基础薄弱, 受技术、人才、资金等条件制约, 尚未实现数字化制造转型, 距离智能制造还有很大 落差。从数量上来看, 这部分企业占制造企业相当 大的比例, 是当前和今后推进智能制造必须解决的 首要难题。相关企业应结合发展实际需求, 扎实完 成数字化制造 “补课”, 为迈向更高水平的智能制 造打好扎实基础。

\section{（二）数字化网络化制造}

作为第二代智能制造的基本范式, 数字化网络 化制造基于网络技术在制造业中广泛应用而形成, 其本质是 “互联网 + 数字化制造”。近年来, 我国 工业界抓牢互联网技术发展赋予制造业的难得机 遇, 推动数字化网络化制造迅猛发展, 一批制造企 业实现了数字化网络化转型升级。

部分数字化基础较好的企业, 在数字化基础上 大力引进网络化技术, 迅速转型为数字化网络化制 造企业。例如, 三一重工股份有限公司自 2008 年
启动工程机械设备数字化设计制造运维的探索, 数 字化转型步伐坚实; 近年来紧跟工业互联网发展浪 潮, 布局建设基于设备全球互联的供应物联网平台, 实现了装备、物料、人员的信息连接，进而形成产 业链维度上的工业互联网平台方案; 横向拓展多个 行业, 形成跨行业、跨领域的通用型工业互联网平 台, 在数字化网络化制造的强力驱动下快速成长为 工程机械制造领域的领军企业 [11]。

部分数字化基础薄弱的企业, 一方面积极完成 数字化 “补课”, 另一方面依托网络化技术来快速 转型为数字化网络化制造企业。例如, 浙江春风动 力股份有限公司是一家摩托车制造企业, 原先数字 化基础薄弱; 2012 年起开展数字化制造 “补课” 的 同时, 采用 “以高打低” 的策略, 谋划建设 “制造 云、电商云、物流云、设计云、流程云”, 开发车 联网平台、消费者终端定制系统, 实现贯穿顾客需 求、研发设计、订单管理、供应链协同、销售配送、 到售后服务的全产业链数据驱动管理; 显著提升市 场需求发掘和快速响应能力、大规模个性化定制产 品快速交付与成本控制能力, 成功转型为具有国际 竞争力的高档摩托车和后市场用品供应商。

\section{（三）数字化网络化智能化制造}

数字化网络化智能化制造是新一代 $\mathrm{AI}$ 技术与 制造业深度融合而形成的新一代智能制造，其本质 是 “智能 + 互联网 + 数字化制造”, 代表了智能制 造发展的最新方向和最高水平。制造系统将具备学 习能力、复杂系统建模与优化能力, 制造业将据此 实现真正意义上的智能制造。

近年来, 我国应对新一轮科技革命和产业变革 机遇, 加速探索和部署新一代智能制造。工业界和 科技界积极推进 “智能制造和机器人” 重大项目, 聚焦新一代智能制造的理论研究、技术突破、产品 研发。目前, 新一代智能制造技术在我国还处于探 索和实验阶段, 主要应用在产品质量控制、装备远 程运维、生产优化调度等方向, 未来应用场景将更 加多样、发展空间更为广阔。

未来 5 年是我国制造业发展全面创新升级的重 要阶段, 应延续 “并行推进、融合发展” 的技术路 线。一方面, 注重夯实基础, 稳步推进企业特别是 中小企业补齐数字化制造 “课程”，基本实现数字 化转型升级; 另一方面, 实施创新引领, 牢牢把握 
互联网、大数据、AI 等新一代信息技术赋予制造业 发展突破的良机, 着力推进“互联网 + 数字化制造”, 基本实现数字化网络化制造推广应用, 兼顾新一代 智能制造的探索推进和创新突破。

\section{四、智能制造是制造企业实现创新升级的主 要途径}

智能制造作为一个大系统，贯穿于设计、制 造、服务等产品全生命周期的各个环节, 关联制造 系统优化集成, 支撑实现制造的数字化网络化智能 化 [12]; 将先进制造技术与数字化网络化智能化赋 能技术深度融合, 推动制造企业产品创新、生产创 新、模式创新、集成创新的整体突破 [9]。我国制 造企业要实现智能化转型升级, 应注重创新驱动、 因企制宜、系统谋划、统筹推进。一方面, 持续开 展制造业技术的原始创新积累, 这是根本性的, 也 是相关企业安身立命的基础; 另一方面, 利用革命 性的共性赋能技术——数字化网络化智能化技术, 对制造技术进行赋能升级、集成创新, 这是开拓性、 普惠性的, 适用于各行业、各种类的制造企业, 也 是赢得市场竞争的关键。

\section{（一）智能产品创新}

制造产品、制造装备是智能制造的主要组成部 分, 前者是智能制造的价值载体, 后者是智能制造 的重要前提。新一代智能制造技术的发展进步, 推 动制造产品、制造装备从 “数字一代” 整体提升至 “智能一代”, 在提高产品功能、性能、市场竞争力 方面具有根本性优势 [9]。

高速铁路作为新一代铁路运输系统, 广泛应用 移动通信、北斗卫星导航、云计算、物联网、大数 据、 $\mathrm{AI}$ 等技术, 具有对高速列车、固定基础设施、 行车环境信息的全面感知、泛在互联、融合处理、 优化决策能力, 可综合利用铁路系统的空间、时间、 人力等资源, 实现铁路运输生产、运营管理、经营 决策等全过程优化 [13]。

\section{（二）智能生产创新}

智能生产也是智能制造的重要组成部分, 主要 载体是智能工厂。智能工厂采用数字化网络化智能 化共性技术来推动生产过程优化, 提升生产系统的
性能、功能、质量、效益。在今后相当长的时期内, 智能装备、智能生产线、智能车间、智能工厂等企 业生产系统的优化升级, 是推进智能制造的重要方 面 [9]。

离散型智能工厂应用数字化网络化智能化技 术, 升级加工质量、优化加工工艺、保障加工装备、 完善生产调度和管理, 提高企业生产制造水平和市 场响应能力。例如, 陕西法士特汽车传动集团公司 2006 年启动企业数字化网络化转型, 重点升级高档 数控机床与工业机器人、智能传感与控制装备、智 能检测与装配装备等核心技术装备, 形成了装备与 装备、装备与管理系统之间的互联互通与高度集成 能力; 产品质量和生产效率大幅提高, 万元产值可 控成本、库存资金占用、产品研发周期等关键指标 大幅提升, 取得了行业优势地位。

流程工业的产能高度集中, 生产工艺、装备、 自动化水平高, 具有较好的数字化网络化实施基 础。加快推进新一代智能制造技术的应用, 推动企 业生产运行真正实现安全、可靠、高效、绿色。例 如, 中国石化九江分公司建立了数字化监测和优化 系统, 遍及 “供、产、转、输、耗” 全流程, 覆盖 计划调度、安全环保、装置操作、能源管理、信息 技术管控等业务领域; 实现了以自动化、实时化、 可视化、模型化、集成化为特征的数字化网络化应 用, 提质增效作用明显, 成为行业解决方案的经典 案例 [14]。

\section{（三）智能服务创新与制造业新模式、新业态}

智能制造是供给侧结构性变革推动力之一。在 智能制造技术支持下, 制造业的生产模式、组织模 式、产业模式都将发生革命性变化, 最终将实现制 造从 “以产品为中心” 向 “以用户为中心” 的根本 性转变 [9]。

一是制造业生产模式从大规模流水线生产转向 规模定制化生产 [1]。依托互联网, 制造企业与客 户、市场的联系更为密切, 企业生产与客户需求直 接对接, 以此优化企业生产资源配置, 高效、经济、 个性化地满足用户需求。例如, 佛山维尚家具制造 有限公司依托网络化平台为用户提供产品定制解决 方案, 从传统家具生产厂转型成为规模个性化定制 的家具生产企业, 提高市场竞争力并取得良好经济 效益 [15]。 
二是制造业产业模式从生产型制造向服务型制 造转变。数字化网络化智能化技术的广泛应用, 为 企业产业链各环节的附加值增值提供了充分的可能 性, 加快了企业高附加值产业链条向上下游两端延 伸的速度，促使企业更快从 “以产品为中心” 向 “以 用户为中心” 转变。例如, 陕西鼓风机 (集团) 有 限公司配置了运行装备远程监测系统, 为客户提供 能量转换领域的个性化、定制化、系统化解决方 案 [16]; 新疆金风科技股份有限公司发展了智能化 大型风电场运维服务系统, 为客户提供风电智能监 控、智能运维、风电机组故障智能诊断与预警等服 务 [17]。这些企业依托数字化网络化智能化技术与 传统业务的结合，快速实现了从产品制造企业向系 统解决方案提供商、服务型制造商的转变。

三是制造业组织模式从企业竞争与垄断走向企 业竞争与协同合作。信息网络、物流系统方便快捷, 企业资源全产业链条的优化配置更加便利, 生产涉 及的物质流、能量流、资金流、信息流更加畅通透 明，企业的设计、生产、销售、服务等活动有望实 现分解、外包、众包, 充分调动国内国际资源。生 产制造、设计创新、制造服务等环节实现协同与共 享，制造企业之间将形成合作共赢的生态。

\section{（四）智能制造支撑系统与智能制造系统集成创新}

智能制造支撑系统是发展智能制造的技术基础 设施, 是制造企业从数字化向网络化、智能化迈进 的关键所在。智能制造系统集成创新促进智能制造 整体效能的提升，推动制造各功能系统集成为新一 代智能制造系统。发展和运用工业互联网、智能制 造云平台, 依靠智能制造系统集成创新来推动企业 实施智能转型。

工业互联网络是智能制造关键网络基础设施, 低时延、高可靠、广覆盖 [18], 主要为企业提供基 础信息支撑服务。我国实施了 “工业互联网工程”, 从网络、平台、安全三方面推进智能制造基础设施 建设和技术升级, 为智能制造提供了有力支撑。智 能制造云平台以泛在网络技术为基础、以用户为中 心，“人、机、物” 深度融合，为制造企业提供技 术支撑服务。一批智能制造云平台投入产业应用并 取得良好成效，如阿里云、华为云、树根互联、航 天云网等。

智能制造系统集成创新在支撑系统的支持下，
集成和优化诸多功能子系统，促使企业智能制造从 局部优化升级到全局优化。例如, 安徽海螺集团公 司综合运用移动物联网、数据传感监测、信息交互 集成、自适应控制等先进技术，建立起了覆盖水泥 生产全环节的系统智能优化控制, 实现了工厂运 行自动化、故障预控化、管理可视化、全要素协 同化、企业决策智能化 [18]; 通过及时高效的转型 升级, 成为世界级水泥生产企业。海尔集团发展 了 COSMOPlat 工业互联网平台, 将用户、供应链、 设备互联互通, 面向企业提供互联工厂建设、大规 模定制、大数据增值、供应链金融、协同制造、知 识共享、检测与认证、设备维保等智能服务, 实现 产业链相关资源的集成优化; 相关革新走在了世界 家电产业链的前列 [19]。

\section{五、结语}

进入 “十三五” 时期以来, 我国以智能制造为 主攻方向推动制造业创新发展转型升级, 取得了良 好效果; 新形势下, 我国智能制造的发展要久久为 功, 坚定不移地推进下去。我国智能制造的应用推 广将进一步提速, 加快推动智能制造, 以数字化、 网络化、智能化升级为抓手, 分行业、分区域差异 化实施; 结合行业特色, 聚焦研发、生产、运维等 关键环节开展智能制造; 加快第五代移动通信、大 数据、AI 等新一代信息技术与制造业深度融合, 注 重产品创新、生产创新、模式创新、制造系统集成 创新, 提升制造业整体的智能制造水平, 提高质量 效益，向产业链高端发展。

\section{参考文献}

[1] 周济. 全力推动传统制造业优化升级 坚定不移建设制造强国 [J]. 中国工业和信息化, 2020 (1): 28-33.

Zhou J. Fully promote the optimization and upgrading of traditional manufacturing industry and unswervingly build a strong manufacturing country $[\mathrm{J}]$. China Industry and Information Technology, 2020 (1): 28-33.

[2] 周济. 智能制造——“国制造 2025”的主攻方向 [J]. 中国机械 工程, 2015, 26(17): 2273-2284.

Zhou J. Intelligent manufacturing_—Main direction of "Made in China 2025" [J]. China Mechanical Engineering, 2015, 26(17): 2273-2284

[3] 朱高峰. 从制造大国到制造强国 [J]. 清华管理评论, 2020 (3): 6-14.

Zhu G F. From a large manufacturing country to a world 
manufacturing power [J]. Tsinghua Business Review, 2020 (3): 6-14.

[4] Zhou J, Li P G, Zhou Y H, et al. Toward new-generation intelligent manufacturing [J]. Engineering, 2018, 4(1): 11-20.

[5] Zhou Y, Zang J Y, Miao Z Z, et al. Upgrading pathways of intelligent manufacturing in China: Transitioning across technological paradigms [J]. Engineering, 2019, 5(4): 691-701.

[6] “新一代人工智能引领下的智能制造研究”课题组. 中国智能制 造发展战略研究 [J]. 中国工程科学, 2018, 20(4): 1-8.

The Research Group for Research on Intelligent Manufacturing Development Strategy. Research on intelligent manufacturing development strategy in China [J]. Strategic Study of CAE, 2018, 20(4): 1-8.

[7] 张银南, 罗朝盛. 浙江省智能制造产业发展调研和分析 [J]. 科 技和产业, 2019, 19(3): 1-7.

Zhang Y N, Luo C S. Research and analysis on the development of intelligent manufacturing industry in Zhejiang Province [J]. Science Technology and Industry, 2019, 19(3): 1-7.

[8] Zhou J, Zhou Y H, Wang B C, et al. Human-cyber-physical systems (HCPSs) in the context of new-generation intelligent manufacturing [J]. Engineering, 2019, 5(4): 624-636.

[9] 藏冀原, 王柏村, 孟柳, 等. 智能制造的三个基本范式: 从数字 化制造、“互联网+”制造到新一代智能制造 [J]. 中国工程科学, 2018, 20(4): 13-18.

Zang J Y, Wang B C, Meng L, et al. Brief analysis on three basic paradigms of intelligent manufacturing $[\mathrm{J}]$. Strategic Study of CAE, 2018, 20(4): 13-18.

[10] 宁振波, 刘泽. 智能制造基础一数字化 [J]. 金属加工: 冷加工, 2020 (7): 6-8.

Ning Z B, Liu Z. The basis of intelligent manufacturing: Digitalization [J]. Metal Working, 2020 (7): 6-8.

[11] 贺东东. 三一重工: 制造即服务, 数据即价值 [J]. 互联网天地, 2017 (1): 23-25.

He D D. Sany Heavy Industry: Manufacturing as a service, data as value [J]. China Internet, 2017 (1): 23-25.

[12] 《智慧工厂》编辑部. 数字孪生一一信息化智造应用的新趐楚 [J]. 智慧工厂, 2020 (4): 27-28.

Editorial Department of Smart Factory. Digital twin: A new leader in information \& intelligent manufacturing application [J]. Smart Factory, 2020 (4): 27-28.

[13] 王同军. 智能铁路总体架构与发展展望 [J]. 铁路计算机应用,
2018, 27(7): 1-8.

Wang T J. Overall framework and development prospect of intelligent railway [J]. Railway Computer Application, 2018, 27(7): 1-8

[14] 王海龙. 九江石化: 流程型智能制造样本 [J]. 中国工业评论, 2016 (6): 72-77.

Wang H L. SINOPEC Jiujiang company: A sample of process intelligent manufacturing [J]. China Industry Review, 2016 (6): 72-77.

[15] 吴义爽, 盛亚, 蔡宁. 基于互联网+的大规模智能定制研究青岛红领服饰与佛山维尚家具案例 [J]. 中国工业经济, 2016 (4): 127-143.

Wu Y S, Sheng Y, Cai N. Study on mass intelligent customization based on Internet Plus_ Cases of Qingdao Redcollar and Foshan Weishang Furniture [J]. China Industrial Economics, 2016 (4): 127-143.

[16] 付向核. 陕鼓: 砥砥创新凝聚发展动能 [J]. 中国工业和信息化, 2020 (5): 62-68.

Fu X H. ShaanGu: Forging innovation and gathering development momentum [J]. China Industry and Information Technology, 2020 (5): 62-68.

[17] 李飞, 乔晗. 数字技术驱动的工业品服务商业模式演进研 究——金风科技为例 [J]. 管理评论, 2019, 31(8): 295-304.

Li F, Qiao H. Research on the business model evolution of digital technology driven industrial service — A case study of Goldwind [J]. Management Review, 2019, 31(8): 295-304.

[18]《宁波经济》编辑部. 智能制造是培育经济发展新动能的关 键——国家工业和信息化部部长苗圩访谈 [J]. 宁波经济, 2017 (10): 3-5.

Editorial Department of Ningbo Economy. Intelligent manufacturing is the key to cultivating new momentum for economic development: Interview with Miao Wei, Minister of the Ministry of Industry and Information Technology [J]. Ningbo Economy, 2017 (10): 3-5.

[19] 吕文晶, 陈劲, 刘进. 工业互联网的智能制造模式与企业平台 建设一一基于海尔集团的案例研究 [J]. 中国软科学, 2019 (7): $1-13$.

Lyu W J, Chen J, Liu J. Intelligent manufacturing and firm-level platform building in industrial Internet: A case study of Haier [J]. China Soft Science, 2019 (7): 1-13. 